\title{
MATHEMATICAL MODELLING OF THE BRIDGES STRUCTURAL MONITORING I
}

\author{
G.M.T. Rădulescu ${ }^{\text {a, *, A.T.G. Rădulescu }}{ }^{\text {a }}$, M.V.G. Rădulescu ${ }^{\text {a }}$, Sanda Naş ${ }^{\text {a }}$ \\ ${ }^{a}$ Technical University of Cluj Napoca, Faculty of Civil Engineering, Department of Terrestrial Measurement and Cadastre, \\ 25 G. Baritiu St., 400027 Cluj-Napoca, Romania, e-mails: *gmtradulescu@yahoo.com, adrian_r1982@yahoo.com, \\ $\underline{\text { mihairadulescu77@yahoo.com, sanda.nas@ mtc.utcluj.ro }}$
}

Received: 08.03.2015 / Accepted: 19.03.2015 / Revised: 09.04.2015 / Available online: 31.05.2015

DOI: $10.1515 /$ jaes-2015-0011

KEY WORDS: Incheon Grand Bridge, Structural Health Monitoring, Mathematical Model, Sensors, Steel Structural Element

\begin{abstract}
:
Structural Health Monitoring is an extremely complex and relatively expensive activity, and the current offer of tools, methods and technologies is varied, which can lead to a virtually high number of structural monitoring systems that can be customized for each case. In time, the monitoring of bridges became the engine for the development of SHM tools, methods and technologies, or manager monitoring systems. The case study, in continuous quasi-static condition, was performed on Incheon Grand Bridge South Korea. Tracking the behaviour of an objective under the influence of sunshine is performed by VCE Vienna Consulting Engineers ZT GmbH. This paper presents the effect of sunshine on a steel structural element, the first lamella front North line, by comparing data pairs that reflect the cause: steel temperature and the effect: the movement of a sensor mounted on the structural element. The analysis was performed using several software dedicated to mathematical modelling, trying to establish different mathematical models that can be tested and validated.
\end{abstract}

\section{INTRODUCTION}

\subsection{General considerations of the Structural Health Monitoring}

Tracking the behaviour over time of land and constructions has always been a distinct branch of engineering surveying and although work in this field, finding movements of resistance elements tracked in a regime close to the static, a few millimetres per year has been integrated into Structural Health Monitoring, it is clear that any construction in the category of bridges (with exceptional design parameters) or very tall buildings should be monitored both in static regime, as a result of subsidence, landslides and the rheology of construction materials, and in dynamic regime, the effect of wind, sunshine plus bridge traffic (Chang,
F.K.,et all, 1999, Dong Y., 2010, Mufti A. et al., 2009, Rădulescu G.M.T., 2015).

To have a unified monitoring concept "tracking the behaviour of land and buildings" had to be included in "Structural Health Monitoring", the surveying activity specific to the field, gaining the attribute "Surveying Structural Dynamic Monitoring". Structural Health Monitoring, however, is a much more comprehensive field because it includes the health of a building considered as a whole, not only in terms of geometry and motion parameters produced by exciting forces. Tracking behaviour over time in dynamic regime appeared and was formed as a need to monitoring the behavior of structures in this regime. Buildings with very bold and innovative design features required in situ study of the objectives, 
both during execution - and post-execution (Ajiboye O., 2010, Gikas, V. and Sakellariou, M.,2008, Housner G. et al., 1997, Merit E., 2011, Radulescu A.T.G., 2013). This process checks if the actual behaviour falls under the project specifications. The opportunity of this new branch of Science of Terrestrial Measurements appeared in the 1970s, but has developed at an accelerated pace in the last 20 , primarily due to projects involving the construction of bridges and very tall buildings, where it contributed significantly in the execution by developing new tools and technologies. An effect of those anterior presented was reconsideration of calculation methods, of standards, of concepts regarding mathematical modelling of the designing process of constructions, but it must be pointed a very important fact: "no design method can be validated unless after an analysis regarding the behaviour through execution and in time of the construction under the action of disturbing factor's action, wind, earthquake, unequal sunny, at this chapter the geodesic measurements being the ones that give possible answers". Modern continuous methods, appealing to modern techniques (usually sensory), do not exclude but complement methods considered classic, so that the monitoring of the health of constructions now comprises all these methods, from middle precision geometric levelling for static analysis of settlements to the use of fibre optic sensors and to monitoring the oscillations of structures in kinematic regime (Chang, F.K., et all, 1999).

\subsection{Presentation of the studied structure, Incheon Bridge}

The Incheon Bridge (figure 1) is South Korea's longest spanning cable-stayed bridge. In comparison, the Incheon Bridge is the world's seventh longest cable-stayed bridge (VCE-Vienna Consulting Engineers, 2009-2015, http://www. incheonbridge.com/, http://www.vce.at/). At $12.3 \mathrm{~km}$ long with a main cable stayed span of $800 \mathrm{~m}$ the new Incheon Bridge will be one of the five longest of its type in the world. Its $33.4 \mathrm{~m}$ wide steel/concrete composite deck will carry six lanes of traffic $74 \mathrm{~m}$ above the main shipping route in and out of Incheon port and link the new Incheon International Airport on Yongjing Island to the international business district of New Songdo City and the metropolitan districts of South Korea's capital, Seoul. The cable stayed section of the crossing is $1,480 \mathrm{~m}$ long, made up of five spans of $80 \mathrm{~m}, 260 \mathrm{~m}, 800 \mathrm{~m}, 260 \mathrm{~m}$ and, respectively $80 \mathrm{~m}$.

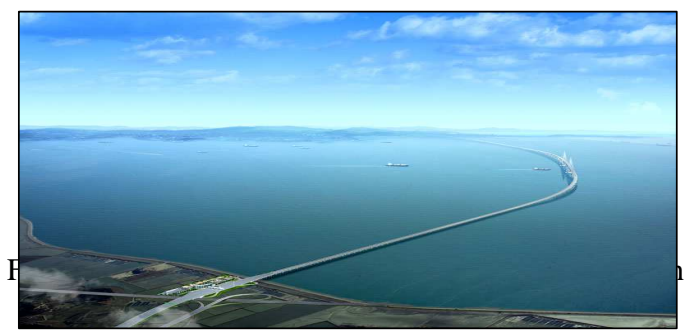

Figure 1. The Incheon Bridge

\subsection{Short presentation of the Structural Monitoring Method}

From the presentation site we quote: „In order to measure the movement of the cable stayed bridge section and the performance of the modular expansion joints of type LR24, a ROBO®CONTROL remote monitoring system was installed at one at the expansion joint locations. This serves to measure the movements of the first, second and last lamella beams of the joint, as well as the entire gap width and air and structure temperatures." (Dong, 2010; Gikas and Sakellariou,, 2008). Figure 2 shows the ultrasonic sensors, and figure 3 shows the position of the RoboControl box, mounted on the structure. The outstanding feature of the UPK series is its high acoustic power combined with small sensor size. Monitoring system consists of 6 UPK category sensors, i.e. 4 UPK 500 sensors (first lamella, second lamella and 24- last, lamella -South, first lamella - North carriagetaway) and 2 UPK2500 sensors (bridge gap-South and North carriagetaway).

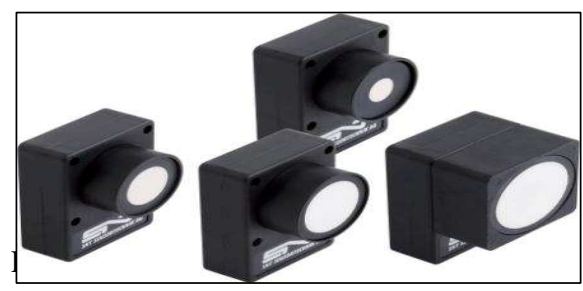

Figure 2. Ultrasonic sensors sonorange UPK (Source : VCE)

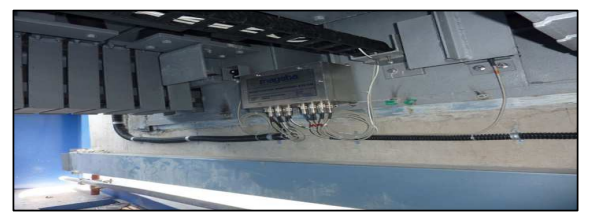

Figure 3. The position of the RoboControl box, mounted on the structure (Source: VCE)

\section{OVERVIEW OF THE DATA OBTAINED IN THE MONITORING PROCESS, THE OPPORTUNITY FOR THEIR SELECTION}

The climate in South Korea is temperate with a lot of rainfall in summer and winters that can get very cold. In Seoul, Incheon bridge area, the average January temperature ranges from $-7^{\circ} \mathrm{C}$ to $1^{\circ} \mathrm{C}$, slightly lower in February, and the average July temperature ranges between $22^{\circ} \mathrm{C}$ and $29^{\circ} \mathrm{C}$, slightly higher in August. The company that performs the monitoring is VCE Vienna Consulting Engineers ZT GmbH. The company has provided us, from June 1, 2009, the date of commencement of the action until today, the date of completion of this paper, December 23, 2014, a huge amount of initial data $-194,881$ for nine parameters (similar to those in Table 1.), so it could be formed a total of 1,753,929 possible pairs of correlations In this conditions, we have decided to make a selection of data for the year 2013 and after that the selection of four significant months from 2013. Table 1 shows the extreme 
values of air temperatures for the period in which the monitoring was made (which continues today) and Table 2 shows the total number of data pairs for different monitoring periods and different intervals between measured data.

\begin{tabular}{|l|r|r|r|}
\hline Moment of Recording & Min. & Max. & Dif. \\
\hline $\begin{array}{l}\text { Month/Day/Year; every } \\
15 \text { minutes }\end{array}$ & $\begin{array}{r}7 / 2 / 2013 \\
21: 28\end{array}$ & $\begin{array}{r}8 / 6 / 2012 \\
5: 58\end{array}$ & $\begin{array}{r}121 \\
\text { Days }\end{array}$ \\
\hline Air temperature [ $\left.{ }^{\circ} \mathrm{C}\right]$ & -14.2 & 36.1 & 50,3 \\
\hline $\begin{array}{l}\text { Movement of 24th } \\
\text { lamella from south line } \\
\text { [m] }\end{array}$ & 0,256 & 0,211 & 0,045 \\
\hline $\begin{array}{l}\text { Movement of bridge } \\
\text { gap from north line [m] }\end{array}$ & 1,676 & 0,861 & 0,815 \\
\hline $\begin{array}{l}\text { Movement of bridge } \\
\text { gap from south line [m] }\end{array}$ & 1,696 & 0,853 & 0,843 \\
\hline $\begin{array}{l}\text { Movement of first } \\
\text { lamella from north line } \\
\text { [m] }\end{array}$ & 0,156 & 0,101 & 0,055 \\
\hline $\begin{array}{l}\text { Movement of first } \\
\text { lamella from south line } \\
\text { [m] }\end{array}$ & 0,139 & 0,083 & 0,056 \\
\hline $\begin{array}{l}\text { Movement of second } \\
\text { lamella from south line } \\
\text { [m] }\end{array}$ & 0,285 & 0,168 & 0,117 \\
\hline $\begin{array}{l}\text { Temperature in the } \\
\text { ROBO-CONTROL box } \\
{\left[{ }^{\circ} \mathrm{C}\right]}\end{array}$ & 5,9 & 34,5 & 28,4 \\
\hline $\begin{array}{l}\text { Temperature of steel } \\
\text { structure [ }{ }^{\circ} \mathrm{C} \text { ] }\end{array}$ & $-15,0$ & 34,7 & 49,7 \\
\hline
\end{tabular}

Table 1. The extreme values for recordings made 02.02.2009-23.12.2014, every 15 minutes

(Source: Authors/VCE)

\begin{tabular}{|c|c|c|c|}
\hline No. & Period & $\begin{array}{l}\text { Interval } \\
\text { between } \\
\text { measure } \\
\text { ments }\end{array}$ & $\begin{array}{l}\text { No. of processed data } \\
\text { pairs }\end{array}$ \\
\hline 1. & \multirow{4}{*}{$\begin{array}{l}2009- \\
2014\end{array}$} & 15 Min. & 194.881 \\
\hline 2. & & $1 \mathrm{H}$ & 48.720 \\
\hline 3. & & $2 \mathrm{H}$ & 24.360 \\
\hline 4. & & $4 \mathrm{H}$ & 12.180 \\
\hline 5. & \multirow[t]{4}{*}{2013} & 15 Min. & 35.024 \\
\hline 6. & & $1 \mathrm{H}$ & 8756 \\
\hline 7. & & $2 \mathrm{H}$ & 4378 \\
\hline 8. & & $4 \mathrm{H}$ & 2189 \\
\hline 9. & \multirow{4}{*}{$\begin{array}{l}2013,4 \\
\text { Month } \\
\text { (II, V, } \\
\text { VIII, XI) }\end{array}$} & 15 Min. & 11.616 \\
\hline 10. & & $1 \mathrm{H}$ & 2.904 \\
\hline 11. & & $2 \mathrm{H}$ & 1.452 \\
\hline 12. & & $4 \mathrm{H}$ & 726 \\
\hline
\end{tabular}

Table 2. The amounts of possible combinations for different monitoring periods at various intervals

(Source: VCE)
Heat transfer, also called thermal transfer, is the heat flow from a system with a high temperature to a lower temperature system, fundamental for the second law of thermodynamics. Atmospheric heat transfer in the material making up the monitored structural element is done by thermal conduction, and it is the mission of the designer to determine the expected effects of this process. Conduction of heat is defined as the transfer of heat from the higher temperature of certain particles to lower temperature ones, which are in contact. It is the current mode of transmission of heat in solids and is based on molecular movements characterized by a lack of macroscopic molecular movements. Through the mathematical models created by the author it is possible to verify previous assumptions, based on which the resistance structure of the monitored target was designed. Note that these mathematical models are based on the loco-object measurement data made during the monitoring process. First, we chose just one year 2013, to process data, because having a temperate climate the range of temperature variations is similar between years.

Second, we chose what data pairs we think would be interesting and useful to process in order to create mathematical models. After some initial tests, we stopped at these cases:

1. The way in which, for different air temperatures, heat transfer is made to and from the steel, material of the examined bridge deck slides. Of course, based on the law stated above, the designer makes predictions that can be very accurate, but under all circumstances the provisions of the project should be checked locoobject. So, in order to have a complete picture of all possible mathematical models which can be created with the available data, we will reduce the number of data in stages so that they can be processed in all four mentioned software, and will finally demonstrate that reducing them to 726 pairs of data (monitoring period 4 months, 4 seasons, 4 hourly intervals between measurements) we obtain a general mathematical model.

2. The most accurate response to heat transfer belongs to the first steel blade of North Line, so we chose to define a mathematical model for this case.

\section{PROCESSING DATA FOR THE FIRST LAMELLA FROM NORTH LINE, DURING THE FOUR CHARACTERISTIC MONTH}

The purpose of mathematical modelling is to describe the relationship between two or more random variables that correspond to the same data set. The problem arises when between the random variable considered there is a consistent relationship based on the intimate nature of the phenomena that underlie them. This connection can be established by analysing data from determinations, in this case structural monitoring measurements, both for the causes (patchy sunshine, wind, traffic, water level variation in the case of bridges, etc.) and the effects - generally, the position of a sensor installed on a structural element. Based on the mathematical model created we can then proceed to perform Forecasts representing an estimation of 
a certain size based on historical data made known. The mathematical regression method (introduced by Pearson in 1908) establishes the link between two or more random variables. In this paper the author will use this method to create mathematical models of the phenomena analyzed. I will analyze both forms of mathematical regression. Linear regression exists when between the dependent variable and independent variables there is a linear relationship, i.e., in this case an independent variable or predictor variable and the other variable as the dependent variable or response variable. Non-linear regression (polynomial, exponential, logarithmic, etc.) exists when between the dependent variable and independent variables there are no linear relationship. Starting from a total of 726 data pairs, representing the temperature of the steel on the OX axis, and the variation of the position of the sensor mounted on the first North line lamella on OY, we made a first selection of data, removing 76 successively, by inserting them in IBM SPSS, software which has the ability to indicate the irrelevant data in a required string of data; after this 650 data pairs remained. Although we eliminated over $10 \%$ of the data through these preliminary iterations, after the first definition of the mathematical model created by linear regression, the results remain irrelevant having a correlation coefficient of less than 0.5 . The rank 1 equation has the form:

$$
y=a+b x+c x^{2}+d x^{3}+e e^{-x}
$$

where: $\mathrm{a}=0.134091413 ; \mathrm{b}=-0.00050815 ; \mathrm{c}=1.08079 \mathrm{e}-$ $05 ; \mathrm{d}=-5.1495 \mathrm{e}-07 ; \mathrm{e}=3.38561 \mathrm{e}-08$; with a correlation coefficient $\mathrm{r}^{2}=0.4214606780$.

Figure 4 shows (from top to bottom) the ratio of processing data introduced in the software, the distribution of measured data relative to the line defined by equation 1 and the percentage size and distribution of residual values. From these images we can see that, although the size of $\mathrm{Y}$ is on a constant downward trend relative to the rise in temperature of the steel (the material of the blade being analyzed), a cloud of points is created, rather than a string of points, and the size of the residual values is great, far from finding a linear variation of the analyzed phenomenon.

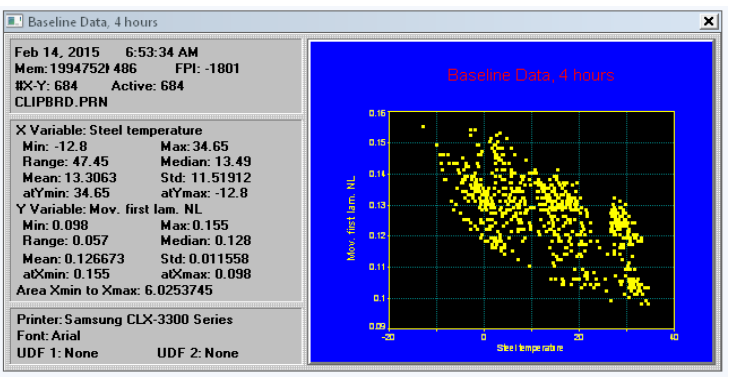

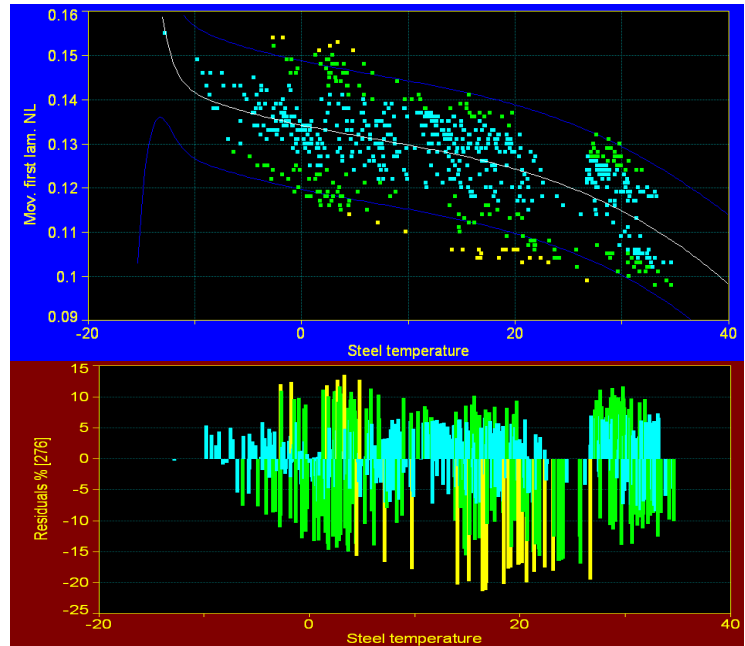

Figure 4. a. Baseline Data, 4 hours; b. The distribution of measured data relative to the line defined by equation $1 ; \mathrm{c}$.

The percentage size and distribution of residual values. (Plot Table Curve 2D)

\begin{tabular}{|c|c|c|}
\hline $\begin{array}{c}\text { X Value } \\
\text { Steel T }\end{array}{ }^{\circ} \mathbf{C}$ & $\begin{array}{c}\text { Y Value } \\
{[\mathbf{m}]}\end{array}$ & $\begin{array}{c}\text { Y Predict } \\
{[\mathbf{m}]}\end{array}$ \\
\hline $\mathbf{1}$ & $\mathbf{2}$ & $\mathbf{3}$ \\
\hline-12.80 & 0.155 & 0.155 \\
\hline-5.11 & 0.140 & 0.137 \\
\hline-0.99 & 0.146 & 0.134 \\
\hline 5.12 & 0.130 & 0.131 \\
\hline 10.32 & 0.140 & 0.129 \\
\hline 15.13 & 0.129 & 0.127 \\
\hline 20.20 & 0.117 & 0.123 \\
\hline 25.70 & 0.106 & 0.119 \\
\hline 30.15 & 0.119 & 0.114 \\
\hline 34.59 & 0.103 & 0.108 \\
\hline
\end{tabular}

Table 3. Comparison of measured sensor position values to predicted values (Source: Authors/ Table Curve 2D)

Considered data in Table 3 we see that there is a mismatch between them. The variation of measured quantities is inconsistent; unlike prediction values whose variation maintains a constant downward trend:

$$
y=a+b x
$$

$\mathrm{a}=0.135173901 ; \mathrm{b}=-0.00063890$, which defines the possible regression line, ranks 29 among equations defined in the software used, and has a low correlation coefficient $\mathrm{r}^{2}=0.4054401834$. In Figure 5 we observe the high degree of dispersion of the data in relation to the regression line, and the confidence interval defined by it (in the figure the violet lines are placed symmetrically relative to the regression line). 


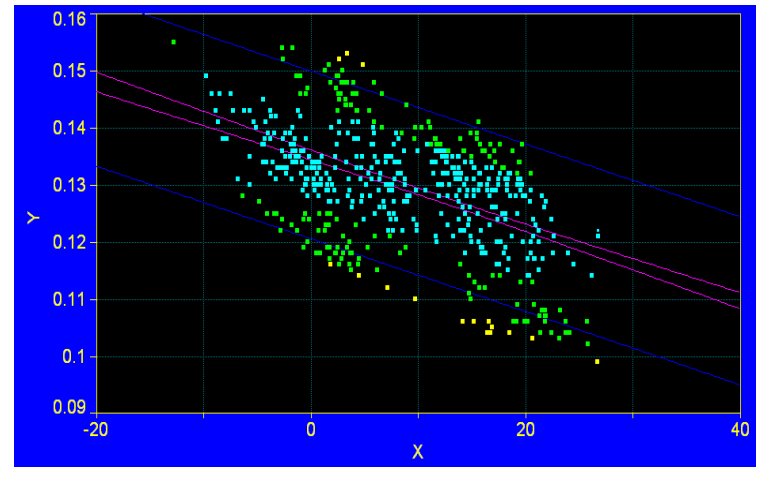

Figure 5. Distribution of measured data in relation to the regression line defined by equation 1 , input data after initial filtration in IBM SPSS. (Plot Table Curve 2D)

Further, we attempt to identify a possible mathematical model with a correlation coefficient greater than 0.9 , by removing successive data that does not fit the trend defined by the regression equation of each data pair. This coefficient is considered relevant for the correlation analyzed. After Iteration no. 1 we eliminated 20 data pairs, and 630 data pairs remain, and the result is a Rank 1 equation identical to equation 1 , differing the parameters a $=0.133703828 ; \mathrm{b}=-0.00030699 ; \mathrm{c}=-8.3886 \mathrm{e}-06 ; \mathrm{d}=-$ 4.7387e-08; $\mathrm{E}=9.11382 \mathrm{e}-07$. The correlation coefficient decreases, becoming $\mathrm{r}^{2}=0.3842808536$. The regression equation is now rank $30, \mathrm{r}^{2}=0.3710995260$; equation $\mathrm{y}=\mathrm{a}+\mathrm{bx}, \mathrm{a}=0.134654211 ; \mathrm{b}=-0.00059167$.

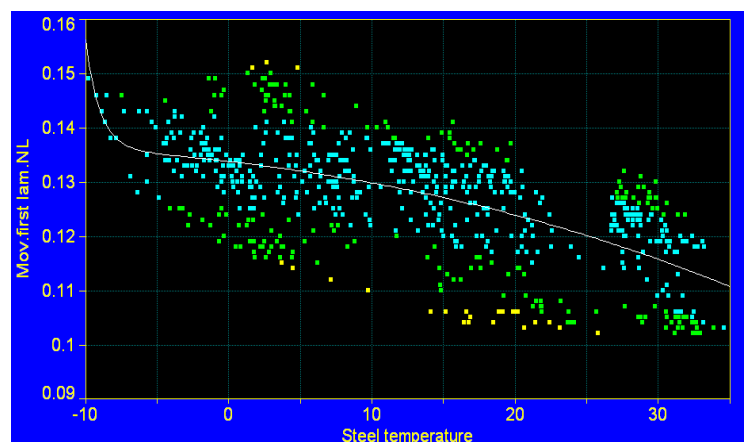

Figure 6. Distribution of measured data in relation to the curve defined by the Rank 1 equation, Input data after iteration no. 1 in IBM SPSS (Plot Table Curve 2D)

The authors further show the results of the next four iterations.

Iteration 2 removes 20 data pairs, and 610 data pairs remain:

Rank 1. Eq., $y=a+b x+c x 2+d x 3+e e-x$

$\mathrm{a}=0.133794798 ; \mathrm{b}=-0.00028827 ; \mathrm{c}=-1.3723 \mathrm{e}-05 ; \mathrm{d}=$ $1.47025 \mathrm{e}-07 ; \mathrm{e}=9.78186 \mathrm{e}-07 ; \mathrm{r}^{2}=0.3598966499$;

Rank 22. Eq., $y=a+b x$,

$\mathrm{a}=0.134465554 ; \mathrm{b}=-0.00056108 ; \quad \mathrm{r}^{2}=0.3508295469$

Iteration 3 removes 17 data pairs, and 593 data pairs remain:

Rank 1. Eq., $y=a+b x+c x 2+d x 3+e x 4$ $\mathrm{a}=0.133275271 ; \mathrm{b}=-0.00037247 ; \mathrm{c}=3.1626 \mathrm{e}-05 ; \mathrm{d}=$ $-3.199 \mathrm{e}-06 ; \mathrm{e}=6.62434 \mathrm{e}-08 ; \mathrm{r}^{2}=0.3373522082$;

Rank 23. Eq., $y=a+b x$

$\mathrm{a}=0.134316087 ; \mathrm{b}=-0.00053176 ; \mathrm{r}^{2}=0.3287332316$. Iteration 4 removes 13 data pairs, and 580 data pairs remain:

Rank 1. $y=a+b x+c x 2+d x 3+e e-x$ $\mathrm{a}=0.133782773 ; \mathrm{b}=-0.00028645 ; \mathrm{c}=-1.3823 \mathrm{e}-05 ; \mathrm{d}$ $=2.00025 \mathrm{e}-07 ; \mathrm{e}=9.85997 \mathrm{e}-07 ; \mathrm{r}^{2}=0.3309304396$;

Rank 23. Eq., $y=a+b x$

$\mathrm{a}=0.134288666 ; \mathrm{b}=-0.00051872 ; \mathrm{r}^{2}=0.3234450506$ Iteration 5 removes 12 data pairs, and 568 data pairs remain:

Rank 1. Eq., $y=a+b x+c x 2+d x 3+e e-x$ $\mathrm{a}=0.133782773 ; \mathrm{b}=-0.00028645 ; \mathrm{c}=-1.3823 \mathrm{e}-05 ; \mathrm{d}$ $=2.00025 \mathrm{e}-07 ; \mathrm{e}=9.85997 \mathrm{e}-07 ; \mathrm{r}^{2}=0.3309304396$;

Rank 23. Eq., $y=a+b x$ $\mathrm{a}=0.134288666 ; \mathrm{b}=-0.00051872 ; \mathrm{r}^{2}=0.3234450506$;

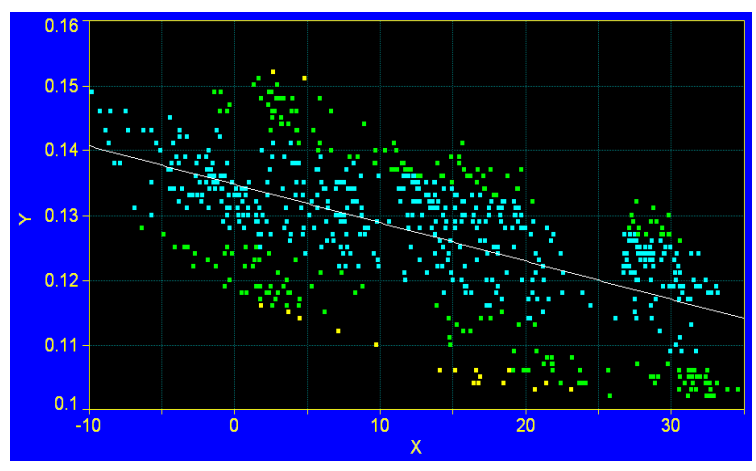

Figure 7. Distribution of measured data in relation to the regression line defined by Equation 4, Input data after iteration no. 2 in IBM SPSS. (Plot Table Curve 2D)

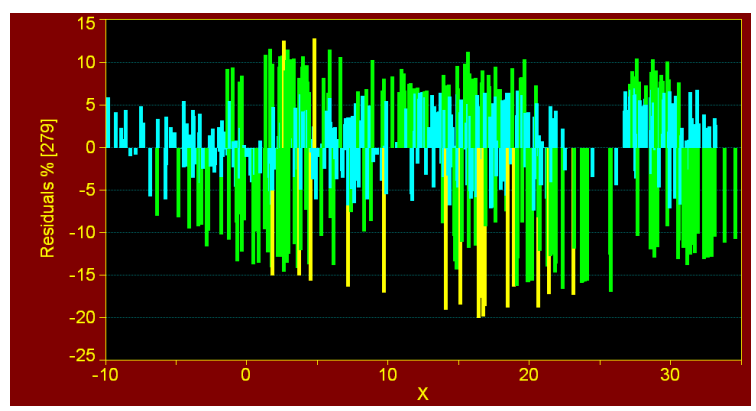

Figure 8. Distribution of residual values in relation to the regression line, Input data after iteration no. 2 in IBM SPSS. (Plot Table Curve 2D) 


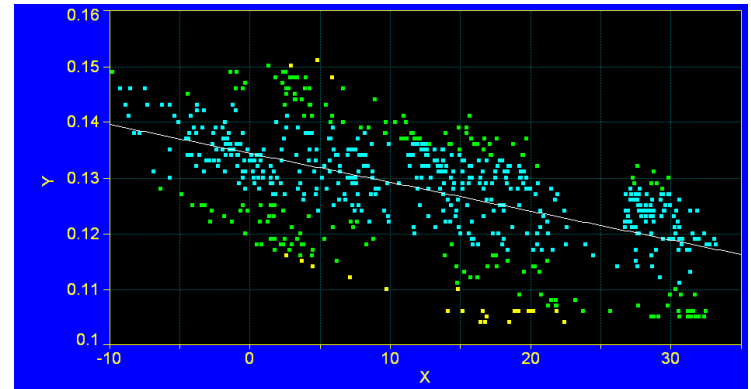

Figure 9. Distribution of measured data in relation to regression line defined by Equation 10, Input data after iteration no. 5 in IBM SPSS. (Plot Table Curve 2D)

We find that, by analyzing equations, correlation coefficients and Figures 6-10, there is no direct link between temperature variation and the position of the sensor mounted on the first North line lamella. The theory on linear regression tells us that "If the point cloud has an elongated geometric shape along an axis, ellipse or oblong parallelogram, there is a linear relation between variables, if the point cloud is shaped like a circle or square there is no linear relation between variables, thus they are independent". This is the case analyzed, and a simple view of Figure 8 shows us this. The authors further demonstrate that this is one of two possible relationships between the effect of temperature and the behaviour of a steel structural element. First we must demonstrate that there is a strong link between atmospheric temperature variation and steel temperature variation, and second we will present a case of another structural element from the same bridge which behaves linearly under the influence of temperature variations.

\section{ANALYSIS OF THE PROPAGATION OF ATMOSPHERIC TEMPERATURE IN STEEL AND CREATING MATHEMATICAL MODEL OF THE DEFORMATION}

We further demonstrate that between atmospheric temperature variation and steel temperature variation there is a very close linear dependence, so this not the reason for the nonlinearity of the behavior of the first North line lamella. Using data from recording made every 4 hours we found that Rank 1 equation obtained through the same process and the value of the coefficients of relationship are as follows: $\mathrm{r}^{2}=0.9581$,

$y=a+b x+c / x+d x^{2}+e / x^{2}++f x^{3}+g / x^{3}+h x^{4}$

$a=-0,30066838 ; b=1,0978933 ; c=0,018578332 ; d=$ 0,$0033183701 ; e=-0,00067539873 ; f=-0,00054381234$; $g=-0,00035223138 ; \mathrm{h}=1,2413653 \mathrm{e}^{-5}$.

We can see a very good correlation factor of 0.958131643 and in Figure 10 we see that, except for a few disparate data, probably occurring because of data transfer, the correlation is perfect, with a range of data variation of up to five degrees and a residual factor of $\pm 2^{\circ} \mathrm{C}$.

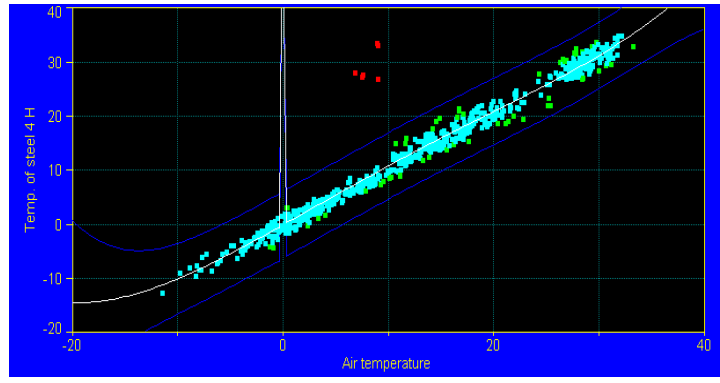

Figure 10. . Steel temperature variation graph relative to changes in atmospheric temperature, the variation range analysis of residual factors (Plot Table Curve 2D)

\section{MATHEMATICAL MODEL OF THE BEHAVIOUR OF THE 24th SOUTH LINE LAMELLA UNDER TEMPERATURE VARIATIONS}

In order to demonstrate another situation, one in which there is a very close connection between cause and effect, in the case of influencing the temperature of the material of the resistance element and its behaviour, expansion or contraction. We chose the correlation between the temperature of the steel (the material of the bridge deck blades) and the movement of the sensor mounted on them, i.e. lamella 24 from the south line of the bridge. We chose three time intervals, respectively data recorded hourly, every two hours, respectively every four hours.

A. Hourly data: Entering the data in the program we obtain 83 equations which define the relationship between the two sets of data, $x$, representing the temperature of the steel and $y=f(x)$ the position of the sensor, relative to a predetermined fixed origin. In general, as a mathematical model we chose the first equation, Rank 1 or the closest one to an operable model. In this case, the first equation is:

$$
y^{0,5}=a+b x+c x^{20}+d x^{3}+e x^{4}
$$

the coefficients are $a=0.494485022 ; b=-0.00063215 ; c=-$ $3.7835 \mathrm{e}^{-0,7} ; d=-7.8368 \mathrm{e}^{-0,7} ; e=1.57508 \mathrm{e}^{-0,8}$

Correlation coefficient $r^{2}=0.8821704827$ showing a highly significant correlation between the input data into the program.

B. Data taken every two hours: Entering the data in the program we obtain 83 equations which define the relationship between the two sets of data, $x$, representing the temperature of the steel and $y=f(x)$ the position of the sensor, relative to a predetermined fixed origin. In general, as a mathematical model we chose the first equation, Rank 1 or the closest one to an operable model. In this case, the first equation is:

$$
y^{0,5}=a+b x+c x^{20}+d x^{3}+e x^{4} \ldots
$$


For this equation the coefficients are: $a=0.494465456$, $b=-0.00060642, c=-9.0723 \mathrm{e}^{-0,7}, d=-9.4767 \mathrm{e}^{-0,7} e=$ $2.05933 \mathrm{e}^{-0,8}$

Although the correlation coefficient $r^{2}=0.8819868406$ decreases slightly, it continues to show a highly significant correlation between the input data into the program.

C. Data taken every four hours: Entering the data in the program we obtain 83 equations which define the relationship between the two sets of data, $x$, representing the temperature of the steel and $y=f(x)$ the position of the sensor, relative to a predetermined fixed origin. In general, as a mathematical model we chose the first equation, Rank 1 or the closest one to an operable model. In this case, the first equation is:

$$
\ln y=a+b x+c \cdot x^{20}+d \cdot x^{3}+e \cdot x^{4}
$$

the coefficients are: $a=-1.40691138 ; b=-0.00242608 ; c=$ $-7.2963 \mathrm{e}^{-0,6} ; d=-3.6588 \mathrm{e}^{-0,6} ; e=7.50831 \mathrm{e}^{-0,8}$

Although the correlation coefficient, $r^{2}=0.9046985517$ surprisingly, increases slightly, it continues to show a highly significant correlation between the input data into the program.

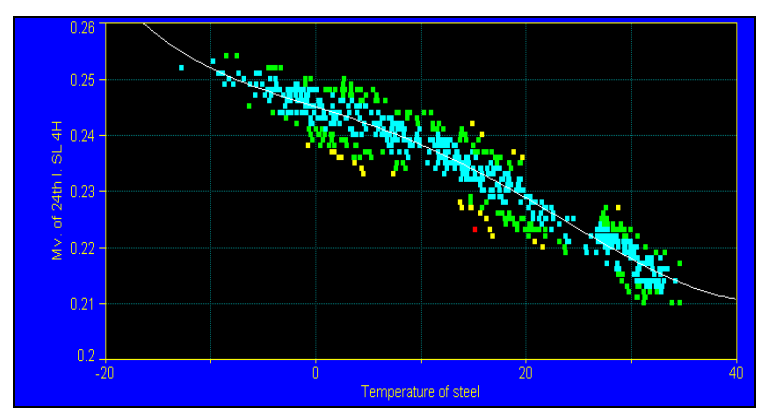

Figure 11. Correlation graph between steel temperature and sensor position on the 24 lamella south line, recording every four hours (Plot Table Curve 2D)

From figure from above showing the correlation graph between the temperature of the steel and the position of the sensor on lamella 24 from the south line, recordings made every four hours, and the five equations-mathematical models shown, it becomes evident that the shape of the graphs, the relationships and indices in the accuracy calculus remain similar; the reduction of the data to a quarter did not significantly affect the results.

Replacing the variable $x=$ steel temperature in the Rank 1 equation $\ln y=a+b x+c x^{2}+d x^{3}+e x^{4} \quad$ leads to values very close to the average ones found in the field, so the correlation is maintained, and it even increases for the density selection every four hours (Table 4).

\begin{tabular}{|c|c|c|c|c|c|}
\hline $\begin{array}{c}\text { T. } \\
{ }^{\circ} \mathrm{C}\end{array}$ & $\begin{array}{c}\text { Rank 1 } \\
\text { eq. }\end{array}$ & \multicolumn{2}{|c|}{$\begin{array}{c}\text { Position from terrain } \\
\text { measurements }\end{array}$} & \multirow{2}{*}{ Approx. } \\
\cline { 3 - 5 } & & Max & Min & Med & \\
\hline 1 & 0.24417 & 0,247 & 0,239 & 0,243 & 0,995 \\
\hline 5 & 0.24149 & 0,248 & 0,237 & 0,242 & 0,995 \\
\hline 10 & 0.23791 & 0,244 & 0,235 & 0,239 & 0,993 \\
\hline 15 & 0.23791 & 0,239 & 0,224 & 0,231 & 0,973 \\
\hline 20 & 0.22798 & 0,226 & 0,222 & 0,240 & 0,988 \\
\hline 25 & 0.22263 & 0,226 & 0,216 & 0,221 & 0,992 \\
\hline 30 & 0.21688 & 0,220 & 0,211 & 0,215 & 0,994 \\
\hline
\end{tabular}

Table 4. Validation of the mathematical model created-The calculation of the approximation accuracy of the mathematical model created on the correlation between steel temperature and sensor position on the 24 lamella south line, for significant temperatures

(Source: Authors/Table Curve 2D)

This comparative analysis shows that for this case (figure 11, table 4) considered the correlation between the response of the displacement sensor under the effect of temperature change it is sufficient to study data taken every four hours, which are similar to those taken every two hours or hourly. Further, the analysis of the data and the construction of the other mathematical models will be made at this data capture density, every four hours.

\section{CONCLUSIONS}

Although the behaviour of a structural element under a specific load or a specific strain may be linear, the analysis of the case study shows that we cannot always define reliable mathematical models that capture the correlation between cause and effect. The heat transfer between two media can take a linear form, but not necessarily. Thus, in this case for example, on the behaviour of the first North line lamella under temperature variations - a resistance component of the Incheon Grand Bridge in Seoul, South Korea - we find that one cannot define a mathematical model of it although, for another similar item made from the same material and having the same structural role, i.e. the bridge deck, for lamella 24 of the South line we were able to define a credible, verified mathematical model, with a very good correlation coefficient.

\section{ACKNOWLEDGEMENTS}

Special thanks to the Vienna Consulting Engineers, from Austria for providing the real-time data and for a very good collaboration with us, initiated in 2009. Known as one of the most important companies carrying out structural monitoring work, led by Professor Helmut Wenzel, the company has made over 6000 projects in over 60 countries.

\section{REFERENCES}

Ajiboye O., 2010, Sensor Computation and Communication for Remote Structural Monitoring, 
http://etd.library. vanderbilt.edu/available/etd-05272009111310/ unrestricted/ Olabode Ajiboye Revised.pdf.

Chang, F.K.,et all, 1999, Structural Health Monitoring, Proceedings of the $2^{\text {nd }}$ International Workshop on Structural Health Monitoring, Stanford, CA, USA.

Dong Y., 2010, Bridges Structural Health Monitoring and Deterioration Detection, Synthesis of Knowledge and Technology, Alaska University Transportation Center, Fairbanks, AK 99775-5900, Final Report.

Gikas, V. and Sakellariou, M.,2008, Settlement analysis of the Mornos earth dam Evidence from Numerical Modeling and Geodetic Monitoring, Engineering Structures. 2008; 30(11):3074-3081.

Housner G. et al., 1997, Developments in the USA in the Field of Structural Control and Monitoring of Civil Infrastructure systems, http://www.iitk.ac.in/nicee/wcee/ article/2217.pdf.

Merit E., 2011, Lessons Learned in Structural Health Monitoring of Bridges Using Advanced Sensor Technology, TRITA-BKN. Bulletin 108, http://www.divaportal.org/ smash/ get/diva2: 456855/.pdf.

Mufti A. et al., 2009, SHM Data Interpretation and Structural Condition Assessment of the Manitoba Golden Boy, Smart Structures and Systems, 6(1), pp.87-90.

Rădulescu G.M.T., 2015, Theoretical and experimental research on structural geometric monitoring of constructions through surveying and alternative methods, Habilitation Thesis, Technical University of Cluj Napoca,

Radulescu A.T.G., 2013, Structural Monitoring Today, Modern Surveying Technologies used to Track Behavior over Time of Buildings, Lap Lambert Academic Publishing.

VCE-Vienna Consulting Engineers, 2009-2015, Permanent Structural Health Monitoring Systems, available at: http://www.brimos.com/DMA/ DMA Frames.

http://www.vce.at/, accesed 2009-2015.

http://www.sntag.ch/, accesed 2009-2015.

http://www.sigmaplot.com/products/tablecurve2d/tablecur ve2d.php.

http://www-01.ibm.com/software/ro/analytics/spss/.

http://www.incheonbridge.com/, accesed 2009-2015. 